\title{
CRITÉRIOS QUE PROFESSORES DE QUÍMICA APONTAM COMO ORIENTADORES DA ESCOLHA DO LIVRO DIDÁTICO
}

\author{
Maria Emilia Caixeta de Castro Lima* \\ Penha Souza Silva**
}

RESUMO: Nesse artigo relatamos uma pesquisa desenvolvida com professores de Química da rede pública estadual de Minas Gerais durante um processo de formação de professores - Imersão - realizado pelo Cecimig, com o objetivo de identificar os principais critérios utilizados pelos professores na escolha do livro didático (LD). Utilizamos os dados obtidos a partir de um questionário respondido por 180 professores de Química. Nossa pesquisa mostrou que $99 \%$ dos professores utilizam livro didático e apontaram os seguintes critérios para escolha: abordagem (conteúdo, contextualização, textos); autor; linguagem clara; diagramação (encadernação, visual); exercícios (quantidade e qualidade); orientações oficiais (PCN e $\mathrm{CBC}$ ). A pesquisa apontou também que os professores têm dificuldades na escolha do LD.

Palavras-chave: Livros Didáticos; Formação de Professores; Ensino de Química.

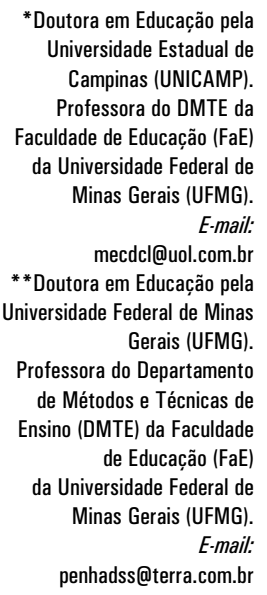

\section{CRITERIA ADOPTED BY CHEMISTRY TEACHERS AS GUIDELINES} FOR THE CHOICE OF TEXTBOOKS

ABSTRACT: In this paper we report a research conducted with Chemistry teachers from public schools of the state of Minas Gerais during a teaching development process (Immersion) carried out by Cecimig, aimed at the identification of the main criteria used by such teachers for the selection of textbooks. We used data obtained from a questionnaire answered by 180 teachers. Our research pointed out that $99 \%$ of the teachers make use of textbooks and are abided by the following criteria for their choice (content, contextualization, texts); author; clear language; layout (biding and visual); exercises (quantity and quality); official guidelines (PCN and $\mathrm{CBC}$ ). The research also pointed out some of the difficulties for the choice of the textbooks.

Keywords: Textbooks; Teacher's Development; Chemistry Teaching.

Nesse artigo relatamos uma pesquisa desenvolvida com professores de Química da rede pública estadual de Minas Gerais. A ideia de realizar tal pesquisa emergiu de um processo de formação de professores realizado pelo Cecimig - Centro de Ensino de Ciências e Matemática da UFMG financiado pela Secretaria de Educação do Estado de Minas Gerais (SEEMG). O curso aconteceu durante os anos de 2006 e 2007 e ficou conhecido como Imersão. Um dos 
tópicos do curso era a análise de livros de didáticos e o planejamento de ensino a partir do livro adotado pelo professor. Esse tópico foi uma exigência da SEEMG, pois a rede de ensino conta com definições de conteúdos para todas as escolas.

O Estado de Minas Gerais foi o primeiro do país a distribuir, gratuitamente, livros didáticos para o nível médio em suas escolas. Desde a primeira iniciativa, os professores fizeram a indicação de dois títulos/autores que gostariam de adotar, por ordem de prioridade. Atualmente, o processo de escolha é feito com base em títulos aprovados pelo Programa Nacional do Livro Didático PNLD.

Pensamos o livro didático (LD) a exemplo do catálogo do bibliotecário de Musil, narrado por Bayard (2007), que, se por um lado, não nos permite conhecer todos os milhões de livros que compõem a grande biblioteca coletiva, produzida pela nossa cultura, dá a ver o mapa dos livros que tal biblioteca contém, e nos permite um sobrevoo na cultura de modo a podermos fazer escolhas das seções da cultura escrita que visitaremos com mais vagar. A atitude de recusa do bibliotecário de Musil a penetrar nos livros é uma atitude sábia de quem cuida dos caminhos e não da paisagem que cada um elege para si:

\footnotetext{
O bibliotecário de Musil, assim, recusa-se a penetrar nos livros, mas não é em absoluto indiferente a eles, e muito menos hostil. Ao contrário, é seu amor pelos livros - mas por todos os livros - que o incita a instalar-se prudentemente na periferia, com medo de que algum interesse excessivamente acentuado por um deles possa conduzi-lo a negligenciar os demais (BAYARD, 2007, p. 28).
}

Não se espera de qualquer iniciante na cultura científica que leia, por exemplo, O Tratado Elementar de Química de Lavoisier (1789), A Origem das Espécies de Darwin (2007), O Desenvolvimento do Pensamento Biológico de Mayr (1998) ou A Mensagem das Estrelas de Galileu Galilei (1987). Desse modo, admitimos que um LD fica na periferia da produção científica, mas incita os estudantes a conhecer partes especializadas de um conhecimento que entrelaça cultura e infinito.

\footnotetext{
A sabedoria do bibliotecário de Musil, para Bayard deve-se, antes de mais nada, à importância que atribui à ideia de totalidade, sugerindo que a verdadeira cultura deve tender à total abrangência, não devendo se reduzir à acumulação de conhecimentos pontuais. E a busca dessa totalidade conduz, por outro lado, a que se dirija um olhar diferente sobre cada livro, ultrapassando sua individualidade para se interessar pelas relações que ele mantém com os outros (BAYARD, 2007, p. 29).
}

Assim, o livro didático seleciona e discorre sobre conteúdos científicos, sociais, históricos e gramaticais que a sociedade, de certo modo, reconhece como legítimos de serem dados a ver a cada nova geração. Constitui-se como instrumento fundamental de apoio à docência na medida em que auxilia o professor na organização da aula e na proposição de atividades. Além disso, como o livro didático representa, muitas vezes, a única fonte de informação científica 
disponível para o aluno e o professor (CARMAGNANI, 1999; SOUZA, 1999), um país que tem 14,1 milhões de analfabetos, de acordo com a Pesquisa Nacional de Domicílios de 2007, não pode abrir mão do livro didático. A biblioteca coletiva, tal como a concebemos, nunca estará mesmo ao alcance de ninguém, mas o desejo e o letramento necessário para saber que ela existe e está franqueada a todos é direito de cidadania e dever do Estado.

Ainda que fôssemos opositores ferrenhos a adoção de livro didático, não se pode desconhecer que esse tópico de discussão tem lugar garantido nos processos de formação docente, pois o livro é um elemento tão presente na sala de aula quanto o próprio professor (MOLINA, 1987). É um objeto familiar ao processo de ensino/aprendizagem e, segundo os órgãos oficiais, o professor é parte integrante no processo de escolha. No caso das instituições privadas de ensino, o professor escolhe o livro e exige que o estudante o adquira (MOLINA, 1987). No caso, das redes públicas, continua sendo o professor quem escolhe e atua como mediador na relação do estudante com o livro (CASSAB \& MARTINS, 2003).

\section{Um breve histórico do curso de Imersão}

No período de maio de 2006 a novembro de 2007, o CECIMIG/ FaE/UFMG assumiu a coordenação do programa de Formação Continuada para professores de Física, Química e Biologia do ensino médio e de Ciências do ensino fundamental da Rede Estadual. O Programa era uma das ações desenvolvidas pela Secretaria de Estado de Educação de Minas Gerais com o objetivo de estudar o os conteúdos básicos comuns. Oficialmente este programa era denominado "Educação Continuada de Professores: Um Estudo dos CBC para a Área de Ciências da Natureza", mas, no âmbito da SEEMG ficou conhecido como Imersão. O porquê do nome deve-se à própria ideia do curso de que é importante o professor poder, em alguns momentos de sua carreira, afastar-se da sala de aula para dedicar-se ao estudo de um modo mais concentrado no tempo. Assim, depois de muitos entendimentos entre os gestores do curso e das políticas públicas da SEEMG chegou-se a uma proposta de receber no Cecimig os professores em turmas de 30 membros, durante um mês, por oito horas diárias. As atividades foram previamente planejadas e, em seguida, desenvolvidas e avaliadas no que se refere aos aprendizados oportunizados a todos os envolvidos. Foram atendidos, aproximadamente, 200 professores de Química, e igual número das demais disciplinas citadas anteriormente.

O curso totalizou 200 horas, sendo 40 por semana, presenciais no Cecimig e mais 40 de socialização da experiência com os colegas da região de onde os professores vieram que seriam desenvolvidas quando de volta às escolas. Para dar suporte a esta iniciativa, foi elaborada uma oficina de projeto de trabalho do docente para essas 40 horas, conhecido como Projeto de Disseminação. 


\section{Tema e problema de pesquisa}

Já nos primeiros encontros com os professores pudemos notar certa angústia dos professores ao se conscientizarem de que a implantação do CBC estava irremediavelmente posta por meio de uma resolução já aprovada pela Assembleia Legislativa e publicada como decisão de governo. A angústia decorreu-se do fato de constatarem que não existe livro escrito de acordo com o CBC, mas uma série de materiais de apoio a serem utilizados conforme interesse e decisão de cada docente. Além disso, a implantação do CBC está relacionada com a avaliação dos estudantes por meio de um banco de itens - questões de múltipla escolha, com quatro alternativas - que o próprio Estado aplica, avalia e analisa os resultados. Embora o CBC não tenha sido pensado como currículo mínimo, mas exigência mínima de aprendizagem, o professor precisa identificar, no livro que adota, os temas, os eixos e os tópicos do $\mathrm{CBC}$ para que não fiquem esquecidos em detrimento de outras escolhas. É preciso dizer, ainda, que o CBC não prescreve uma sequência a ser adotada, mas ideias e relações a serem observadas. A pergunta silenciosa, por vezes timidamente explicitada, que cada professor passou a se fazer é se o livro que ele adotou atenderia ou não ao CBC. Pouco a pouco, alguns iam concluindo que a escolha já feita não era a que ele agora julgava mais adequada. Uma das questões que surgiu foi em relação ao modo como fazemos escolhas de livros: cuidado na análise, corresponsabilização na escolha, bom uso de um "mau" livro, etc. Desse modo, centramos nossa atenção em conversar com os professores sobre as características que atribuíam a um livro que chamavam de bom para ser adotado. Em outras palavras, o cerne da questão foi identificar características que o professor considera relevantes em um livro de Química, caso tenha que indicar um para os alunos da escola em que leciona.

A programação consistia em discutir critérios para auxiliá-los na análise dos livros aprovados no Programa Nacional do Livro Didático para o Ensino Médio (PNLEM) e identificar conteúdos e abordagens teórico-metodológicas que se aproximem daquelas que orientaram as escolhas propostas no CBC de Química. Enfim, ajudar cada um a orientar seus alunos(as) a fazer bom uso do livro que a escola dispuser.

\section{Metodologia}

Com o objetivo de identificar os critérios utilizados pelos professores de Química na escolha do livro didático utilizamos os dados obtidos a partir de um questionário respondido por 180 professores de Química. Os professores participantes desta pesquisa faziam parte de um grupo de formação continuada promovida pela Secretaria de Educação do Estado de Minas Gerais. As questões propostas no questionário já haviam sido utilizadas, em linhas gerais, com professores de Química da rede privada de Belo Horizonte para orientar a escolha de livros didáticos. 
Esse questionário foi aplicado antes de iniciarmos as discussões sobre o uso do livro didático e de apresentarmos alguns critérios de escolha, inclusive os utilizados pelo PNLEM. O objetivo era identificar as concepções deles sobre características dos LD e os critérios de escolha que utilizavam.

A partir das respostas fornecidas pelos professores, eram realizadas as discussões coletivas, seguidas de leitura e discussão de artigos que lidam com o tema. Uma análise mais detida dos dados foi realizada posteriormente com o auxílio de um estudante do curso de licenciatura em Química. É importante relembrar que esses professores deveriam estar familiarizados com a prática de adoção de livros nos moldes do PNLEM, implantado em 2004.

Em síntese, o questionário perguntava:

Quando você (professor) escolhe um livro didático para ser adotado, o que você olha primeiro?

Essa pergunta foi propositalmente aberta, de modo a evitar que o professor escolhesse critérios indicados circunscritos às categorias eleitas pelos pesquisadores, que pudessem ser entendidos como antecipação de desejo de uma determinada resposta ou que excluísse algum critério que não julgássemos importantes de serem evocados.

A questão seguinte pedia para falarem das características consideradas relevantes a um livro de Química para que seja adotado por ele. Depois, o professor deveria "contar" o modo ou as circunstâncias em que o livro didático é usado por ele. Entretanto, nenhum deles respondeu essa questão na forma narrativa, se limitaram a fazer indicações ou pequenas descrições.

Por último, o professor deveria dizer qual livro adota atualmente para cada série que leciona, avaliar o grau de satisfação dele com o livro didático de Química (LDQ) e os motivos que os levam a se agradar ou desagradar do livro.

Todas as questões propostas foram seguidas de várias linhas em branco para que os professores pudessem dissertar sobre suas escolhas de modo mais extenso e apontar diferentes critérios que julgassem relevantes mencionar. Como alguns professores trabalham em várias escolas e adotam livros diferentes, todos os que foram citados estão considerados nessa análise.

\section{Resultados e Análise das Respostas}

Na Figura 1 estão representados, por meio de um gráfico de setor, os critérios que os professores indicaram como sendo o que primeiro lhes ocorre avaliar ao proceder à escolha de um LDQ. 
Figura 1: Critério mais relevante na escolha de um LDO

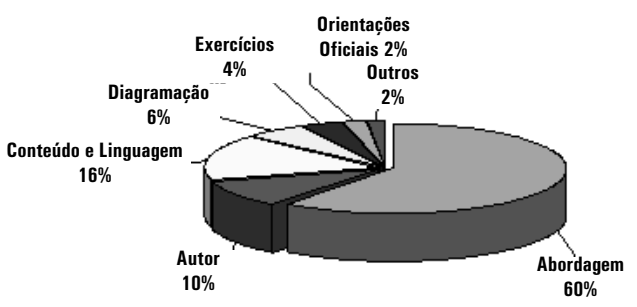

Para 10\% dos professores, o fato de o autor ser conhecido é definidor para a escolha do livro. Esse dado parece nos indicar o motivo de alguns autores permanecerem no mercado, mesmo quando surgem outros livros que apresentam escolhas diferentes daquelas que são amplamente criticadas pelo professor, tais como a memorização, a extensão enciclopédica, a fragmentação, etc.

Linguagem e conteúdo são critérios apontados por 16\% dos professores pesquisados. Esses critérios são apresentados de modo vago sem maiores adjetivações, exemplificações ou argumentação por parte dos professores, o que indica a necessidade de investigar, de modo mais verticalizado, o que estão dizendo até para sabermos o que indicam como "linguagem e conteúdo adequados". Quanto aos 4\% dos professores que indicaram os exercícios como o principal critério para escolha do LD, observam, segundo eles, a quantidade de exercícios propostos (ter muitos exercícios), a qualidade (sic) e o grau de dificuldade para a resolução (exercícios de fácil entendimento; exercícios bons) e o tipo de exercícios (questões abertas e múltipla escolha e dos vestibulares mais recentes do país).

$60 \%$ dos professores pesquisados indicaram espontaneamente como sendo mais importante olhar a abordagem do conteúdo quando têm que analisar LDQ. Pelas respostas dadas notamos que alguns estão se referindo à organização do conteúdo, outros à sequência que o livro segue, outros se a apresentação do conteúdo é interessante (se a apresentação do conteúdo é correta e interessante; se a forma como é abordado o conteúdo é interessante).

Para compreender melhor os critérios indicados como relevantes a adoção de um livro de Química, vamos examinar 596 características apontadas e categorizadas conforme o Quadro 1. Os mesmos dados estão dispostos em gráfico, como se segue na Figura 2. 
Quadro 1: Características relevantes que um LDO deve apresentar

\begin{tabular}{c|c|c} 
Característica & Respostas dos Professores & Percentual (\%) \\
& & 51 \\
\hline Contextualização & 91 & 14 \\
\hline Adequação ao CBC/PCN/Vestibulares & 26 & 56 \\
\hline Diagramação & 100 & 68 \\
\hline Linguagem & 123 & 49 \\
\hline Experimentação & 89 & 18 \\
\hline Textos & 32 & 44 \\
\hline Abordagem & 80 & 16 \\
\hline Exercícios & 28 & 3 \\
\hline Autoria & 5 & 4 \\
\hline Assessoria pedagógica & 7 & 8
\end{tabular}

Figura 2: Características relevantes que um LDQ deve apresentar

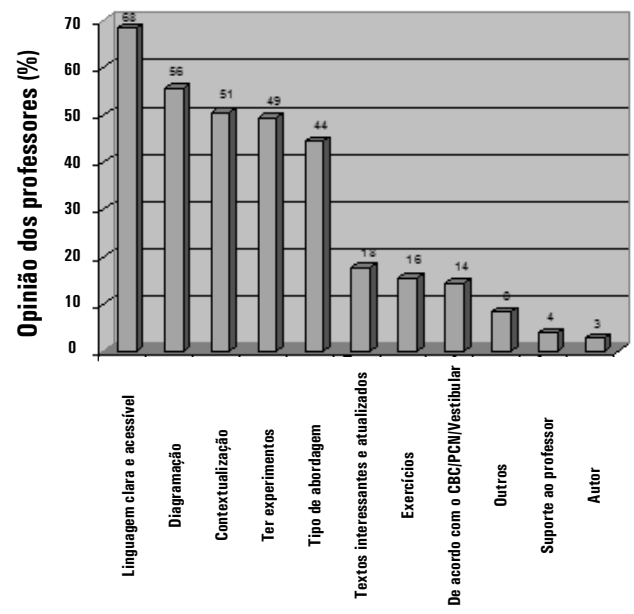

Grosso modo podemos dizer que, o que importa mesmo para o professor é a linguagem, a diagramação, a contextualização, as experimentações e o tipo de abordagem.

Podemos notar que, dentre as características citadas com maior frequência, uma grande preocupação recai sobre a linguagem utilizada nos LDQ e sua aproximação do conteúdo com a realidade dos estudantes.

Para 68\% dos professores, o livro necessita apresentar, uma linguagem clara, objetiva, que esteja adequada aos alunos, conforme ressaltado na Figura 2. Outros modos de adjetivar a linguagem clara é dizer: Informações essenciais; conteúdo objetivo e enxuto; ir direto ao assunto e ter textos de fácil compreensão para os alunos. Essa definição foi mais explorada junto a um pequeno número de professores, os quais disseram que os livros que apresentam textos mais longos e problematizadores, com baixa recorrência a esquemas de memorização, de classificações e poucos exercícios são de linguagem difícil e pouco clara para os estudantes. Assim, podemos concluir que a linguagem chamada de clara e de fácil acesso é aquela que aborda 
superficialmente os fenômenos com pouca ou baixa relativização dos mesmos. Para eles, os estudantes precisam primeiro classificar/separar ligação iônica de covalente, ácido de base, etc. para depois relativizarem o caráter de cada substância. Acreditamos que uma mudança significativa na prática do ensino de Química só deverá ocorrer quando a ênfase que damos à quantidade do que se ensina der lugar à importância conferida à qualidade do que se aprende. $\mathrm{O}$ tempo com o que se ensina é diferente do tempo gasto no que se aprende. Antes que isso ocorra, a pressa em vencer os conteúdos será inimiga dos processos que dão maior ênfase ao desenvolvimento e à formação de conceitos. Embora, atualmente existam muitos estudos sobre linguagem e cognição na educação em Química, não tivemos acesso a trabalhos que tenham investigado o que os professores definem como linguagem clara e acessível.

A diagramação do livro é a segunda característica mais apontada pelos professores. Para 56\% deles, a capa, a qualidade das páginas, textos, figuras, disposição dos conteúdos e gráficos, o peso do livro, o número de páginas ou volume, facilidade no manuseio, etc. contribuem para a escolha do livro didático. $\mathrm{O}$ alto percentual de professores que indicaram a diagramação como fator importante ao se caracterizar um bom livro, pode estar relacionado ao fato de este ser um dos critérios apresentados pelos guias do PNLEM para orientar as escolhas, e também ao fato dos professores de Minas Gerais estarem em contato com essa prática há mais tempo. Além disso, pudemos notar que, nesse critério, os professores incluem a característica do livro de apresentar-se em um volume único ou em três volumes. Alguns professores preferem o volume único, pois, segundo eles, o conteúdo está sempre à mão, ganham em flexibilidade na sequenciação dos conteúdos. Outros preferem o conteúdo dividido em três volumes, pois acreditam que o peso do livro influencia no fato de o aluno levá-lo ou não para a sala de aula. Contudo, pudemos constatar que, em geral, o volume único pesa praticamente o mesmo que qualquer um dos volumes relativos às três séries do ensino médio. A qualidade das páginas, segundo alguns professores se traduz na gramatura e na intensidade do brilho, o que torna o livro mais atrativo esteticamente, principalmente no caso das páginas que contêm gráficos e figuras em geral. Por outro lado, essa qualidade se torna um problema para eles na medida em que o livro fica mais pesado, ruim para fazer cópias digitalizadas de gravuras para compor slides de aula e aumento do preço do livro, o que costuma ser um problema nas escolas privadas de ensino.

A terceira característica mais indicada, segundo $51 \%$ dos pesquisados é a contextualização. Nessa característica incluímos também as referências feitas ao cotidiano, que aparecerem em menor proporção que a expressão contextualização. Contudo, pudemos observar que é indiferente o modo como o contexto aparece no LDQ, se, como mero exemplo, ilustração, curiosidades, abertura de capítulo, de unidade, de uma seção ou, se em contraposição a isso, significa uma situação ou contexto a partir do qual uma história (Química) se desenrola, por onde circulam variados sentidos e se consolida como um significado cientifica- 
mente estabelecido. Não temos dúvida de que essa característica do ensino e dos materiais didáticos orientadora dos documentos oficiais é a mais citada pelos professores quando adjetivam um ensino de qualidade. Contudo, com frequência, usam contexto como sinônimo de cotidiano. Além disso, é preciso aprofundar nas teorias de aprendizagem que sustentam os diferentes papéis atribuídos ao contexto. São inúmeros os contextos que entram em nossa vida por meio da internet, dos jornais e TV, mas não dizem respeito a nós, em absoluto. Desse modo, sabemos que nem todo contexto faz parte do cotidiano dos estudantes, mas, nem por isso, deixa de ter significado social para a humanidade, mesmo que seja distante do nosso dia-a-dia. Entender a contextualização como mero engajamento do estudante, isto é, restrito à motivação, é completamente diferente de entendê-la como trabalho semiótico, esforço de produção de novos sentidos. Acreditamos que, analisar o papel da contextualização, como um fenômeno da linguagem, isto é, numa perspectiva histórico cultural, pode nos ajudar a avançar na escolha de livros didáticos mais eficazes à compreensão dos alunos.

De acordo com Bakhtin, a compreensão é trabalho de produção de sentidos entre a palavra própria e a palavra alheia. Resulta de "um processo de confrontação e interpretação, o que proporciona uma reavaliação, uma modificação e o surgimento de um novo signo na consciência, uma nova palavra interior" (BRAIT, 2005, p. 181). Em outras palavras, "resulta de um esforço de relacionar um signo interior qualquer de que dispomos com outros signos que nos são apresentados no contexto social de trocas verbais e uso de significados veiculados pela linguagem” (BAKHTIN/VOLOCHINOV, 1997, p. 60).

Ver uma coisa, tomar consciência dela pela primeira vez, significa estabelecer uma relação dialógica com a coisa: ela não existe mais só em si e para si, mas para algum outro (já há uma relação entre duas consciências) (BAKHTIN, 1997, p. 343).

Um conceito ou ideia nova, por mais concreto que seja sempre se apoia em coisas já "conhecidas" - mesmo que o conhecido signifique apenas ouvido. A chave para a compreensão está relacionada à relação ou ponto de continuidade que se estabelece entre a novidade e o já conhecido (LIMA, AGUIAR e PAULA, 2009). Os contextos são os meios mais ricos de compreensão no sentido bakhtiniano. Portanto, analisar os modos como os LD apresentam os contextos de ensino faz grande diferença na aprendizagem dos estudantes e nas finalidades que conferimos ao aprendizado da Química no nível médio. Estamos defendendo com isso que há diferenças substanciais nos textos didáticos no que se refere ao modo como o contexto é entendido e utilizado pelo autor e que é possível auxiliar o professor no procedimento de análise de LD com base nessa característica. Em geral o livro usa mais o contexto como engajamento (motivação)? Como exemplo ou aplicação? Como suporte ou "fundo de tela" sob o qual se desenvolvem e formam-se conceitos? Que vantagens e desvantagens existem em cada um desses usos? Que diferenças existem entre a contextualização em 
Química na abordagem do cotidiano (TITO e CANTO, 2004), Química e Sociedade (PEQUIS, 2005) e no Química para o Ensino Médio (MORTIMER e MACHADO, 2002)?

A ocorrência de experimentos foi citada por $49 \%$ dos professores, percentual bastante significativo. Contudo, todos os livros aprovados pelo PNLEM trazem sugestões de experimentos, mas o que está sendo valorizado é o fato de serem simples ou não. Uma pergunta imediatamente feita foi quanto ao uso que o professor faz do livro didático. Como pode ser visto na Figura 3, o uso do livro, como suporte para realização de experimentos, foi apontado por apenas $11 \%$ dos professores investigados. Acreditamos que esse percentual está mais próximo da prática docente relatada por eles durante o curso de Imersão que os $49 \%$ que disseram que a primeira coisa que olham no livro é "ter experimentos". Via de regra, os experimentos que relataram fazer em sala são esporádicos e de caráter demonstrativo. Isso nos parece informar que, no discurso, alguns professores reconhecem a experimentação como um recurso importante para o ensino de Química. Contudo, o valor conferido a essa característica do LD possa estar ligado à satisfação pessoal de conhecer situações experimentais exemplares, haja vista a indicação de 4\% do uso que fazem do LD como suporte à docência.

Dentro ainda do grupo de características apontadas com maior frequência está o que chamaram de tipo de abordagem, com 44\% de ocorrência. A abordagem pode ser entendida como a disposição de apresentação dos conceitos químicos e a existência de textos complementares que ajudam a conferir importância ao estudo da Química. Conforme Cassab e Martins (2003), os professores confundem metodologia com a noção de conteúdo. Neste sentido, um bom livro seria aquele rico em informações e que apresenta todos os conteúdos necessários à prática pedagógica. Contudo, não parece ser esse o sentido conferido pelos professores investigados, na medida em que enumeram indicadores tais como: o livro apresenta sugestão de atividades em grupo criativas e interessantes; apresenta os fenômenos; trata de questões ambientais; traz exemplos práticos; tem sugestão de projetos; está de acordo com o projeto pedagógico da escola; tem história da Química; curiosidades a respeito da Quimica; apresenta atividades variadas; correlaciona fenômeno, modelo e teoria, etc.

Aspectos relacionados à noção de conteúdo foram menos frequentemente indicados, são eles: ausência de erros conceituais; distribuição eletrônica; e conteúdo completo.

Apenas 1\% dos professores disseram não adotar livro didático, enquanto $13 \%$ disseram não usar ou usar raramente o livro adotado. O empenho da SEEMG é de que os estudantes usem o livro e, de que todas as escolas indiquem dois títulos, considerando a ordem de escolha para que um seja enviado aos alunos(as), preferencialmente o primeiro na lista.

Menor importância dizem dar à autoria do livro (3\%). Os principais autores adotados são Tito e Canto (32\%); Grupo PEQUIS (28\%), Feltre (28\%), Bianchi, Abrecht e Maia (6\%) e Mortimer e Machado (4\%) (Quadro 2). A pesquisa revela que os livros mais adotados pertencem a autores já consagrados pelo 
mercado editorial. Entretanto, os livros chamados por eles de alternativos: Química e Sociedade (PEQUIS) e Química para o Ensino Médio (Mortimer e Machado), já somam 32\% da preferência dos professores da rede estadual de Minas Gerais. Chamou-nos a atenção o fato de que a porcentagem de professores que escolheram o livro Química e Sociedade ser igual ao que adotou o livro Fundamentos de Química (Feltre), sendo este último bastante conhecido no mercado de LDQ. Pudemos observar também que, paradoxalmente, o maior índice de insatisfação com a adoção recai sobre o livro de Feltre. Como explicar que, sendo tão conhecido no mercado editorial possa haver uma frustração do professor ao tê-lo adotado?

No geral, 41\% dos professores estão satisfeitos com os LDQ adotados, $45 \%$ estão insatisfeitos e 14\% estão parcialmente satisfeitos. Entretanto, esses números podem ser mais bem explorados quando avaliamos os percentuais de satisfação dos professores sobre o livro que eles utilizam em sala de aula (Figura 4).

Apenas $2 \%$ dos professores mencionam que as orientações oficiais como PCN e CBC de Química são consideradas na hora de escolherem o LD para seus alunos(as). Esse dado pode ser interpretado como uma atitude de resistência às orientações oficiais, a discordância em relação a tais orientações, o julgamento de que todos os LD atuais já incorporaram essas orientações e, portanto, isso não diferencia um livro de outro ou ainda, o desconhecimento de que orientações de governo são sempre polissêmicas, isto é, admitem variados sentidos e, portanto, variados modos de compreendê-las e de traduzi-las em texto didático. É importante ressaltar que os professores participantes desta pesquisa estavam iniciando um programa de formação para implantação de uma proposta curricular oficial da Secretaria de Educação do Estado de Minas Gerais para o ensino de Química. É fato que todos eles tinham conhecimento do CBC já publicado oficialmente como Resolução 666/2005. Esse dado também nos indica o descrédito dessas políticas que são interrompidas tão logo ocorrem mudanças nos governos (LIMA, 2001).

$88 \%$ dos educadores declaram que o LDQ é utilizado como suporte à prática pedagógica na sala de aula. Esse suporte reflete o uso do livro na resolução de exercícios, no acompanhamento pelos alunos da teoria dada, em atividades de interpretação de gráficos, textos e figuras. Mas, apenas 1\% dos professores disse se apoiar na sequência didática apresentada no livro adotado. Isso nos leva a concluir que os professores vem selecionando, nos livros, os conteúdos que julgam mais relevantes para incluírem nos seus planejamentos de ensino. 
Figura 3: Uso que os educadores fazem do LDO em sala de aula

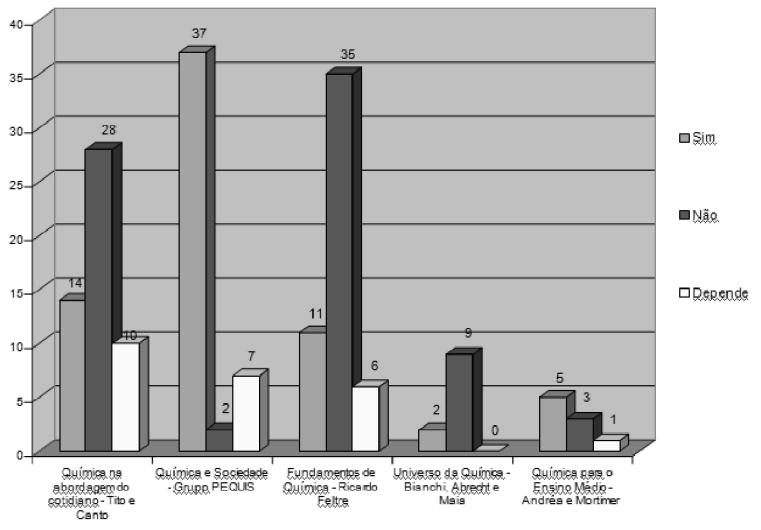

Analisando o gráfico, podemos ver que os livros considerados tradicionais são os que apresentam maior grau de insatisfação. Conforme os depoimentos dos professores, observamos, de forma recorrente nas respostas que, esta insatisfação se deve ao fato dos livros adotados apresentarem ausência de contextualização, presença de erros conceituais, distanciamento dos livros com os PCN e o CBC e a complexidade dos exercícios. O depoimento a seguir ilustra este fato: [O Tito e Canto tem] poucos textos e sempre uso outros livros, acho os exercicios dificeis para meus alunos (Noturno).

Muitos professores relataram que o LDQ não foi adotado mediante seu consentimento. São várias as histórias relatadas pelos professores, durante a Imersão, para a escolha do livro didático. Segundo alguns, a própria direção escolheu o livro, por falta de prazo perante as datas indicadas pela SEEMG. Outros afirmaram que a SEEMG enviou o livro sem nenhuma consulta prévia à escola; outros tiveram oportunidade de escolher, mas o tempo não era suficiente e que, portanto, escolheram dentre os livros à disposição, aquele que era mais conhecido. Ainda, temos os professores que chegaram à escola e o livro já tinha sido adotado por outro professor. Muitas são as queixas dos professores como, por exemplo, o fato de receberem um livro diferente do que foi solicitado, número insuficiente de livros recebidos, correria com que se é feita a escolha no final do ano, livro escolhido por outro colega que já saiu daquela escola e, nos dizeres dos próprios professores "largaram uma bomba para nós". Reconhecemos que a escolha e a distribuição dos livros didáticos precisam ser melhorados. Contudo, tais queixas não abalam nossa convicção quanto à importância do LD. Por isso, não entraremos no mérito de analisar os motivos que levam críticos de LD a discorrerem contra a adoção dos mesmos.

Esses relatos nos ajudam a compreender o motivo do alto grau de insatisfação.

Quanto aos livros considerados alternativos, Química e Sociedade Grupo PEQUIS e Química para o Ensino Médio - Machado e Mortimer, há uma 
grande aceitação devido à metodologia utilizada. Nesse caso, como fator positivo, os professores citam a contextualização do conteúdo e a aproximação aos PCN e CBC. Contudo, alguns professores declaram que encontram dificuldade em utilizá-los por não entenderem a dinâmica do livro e necessitarem fazer adaptações para as aulas.

\section{Considerações Finais}

O presente estudo teve o objetivo de apontar os principais critérios utilizados pelos professores de Química, participantes do programa Imersão, na adoção do LDQ, no contexto do PNLEM.

Para Santos (2006), a escolha do LDQ a ser adotado na escola não é uma tarefa fácil para os professores. Por isso, devido à grande variedade de propostas no mercado, sua escolha deve ser feita de forma criteriosa, considerando diferentes aspectos relacionados à sua abordagem didática. A falta de tempo dos professores, seu envolvimento com as orientações pedagógicas de ensino, a falta de cursos de atualização, a propaganda maciça das editoras, a experiência na docência, são alguns fatores que determinarão a adoção de um livro didático em detrimento de outro.

A dificuldade é escolher um LD que se enquadre na proposta pedagógica de ensino da escola. Os PCN orientam que o ensino deve ser contextualizado e contribuir para a construção de um cidadão crítico. Os professores compreendem a importância de uma abordagem contextualizada, mas, também, estão conscientes das dificuldades de implantação na sala de aula. O livro didático pode ser uma ferramenta que auxilie o professor no desenvolvimento de uma proposta de ensino-aprendizagem que atenda a essas demandas. Entretanto, não basta inundar o mercado com LDQ alternativos e esperar que os educadores realizem uma educação de qualidade. É importante que haja investimento na formação inicial e continuada do professor para que adquira segurança quanto a utilização desses materiais.

Nossa pesquisa mostrou que $99 \%$ dos professores dizem utilizar livro didático. Assim, entendemos que consideram importante esse instrumento no processo de ensino aprendizagem. O LD parece ser o principal meio de informação de um determinado conteúdo disponível para o aluno. É responsável por apresentar praticamente todas as atividades que os professores utilizarão durante as aulas. Ainda, o LD é, juntamente com o professor, o elo de ligação entre a ciência e o cotidiano do aluno.

Com base na nossa pesquisa e nas referências bibliográficas podemos apontar que os principais fatores que levam o professor a escolher um livro didático são:

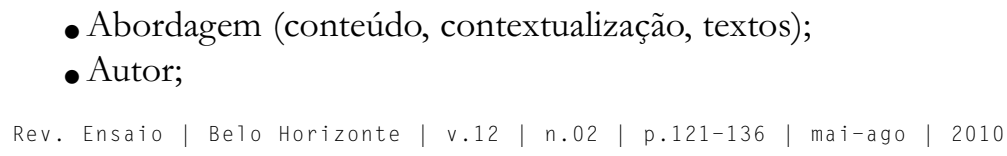


- Linguagem clara;

- Diagramação (encadernação, visual);

- Exercícios (quantidade e qualidade);

- Orientações oficiais (PCN e CBC).

Os professores nem sempre fazem sua escolha após um exame minucioso de várias obras. Ele deixa-se influenciar pela pressão das grandes editoras, colegiado e, muitas vezes, pelos companheiros de profissão que, em consenso, adotam o mesmo autor que já vem sendo utilizado, o que reduz o tempo que disponibilizarão para a preparação das aulas. Outro fator a ser destacado é a falta de tempo para analisar as obras disponíveis no mercado.

A diagramação é outro fator que define a adoção do LD. O forte impacto visual decorrente das ilustrações, gráficos, paginação e encadernação influenciam diretamente na escolha do LD. Dizem por exemplo: livro com figuras coloridas. De fato, um livro visualmente agradável seduz num primeiro contato professores e alunos. $\mathrm{O}$ que aponta um caminho para o aumento da tiragem e da venda dos livros considerados alternativos. Não basta ser um livro didaticamente avançado, é necessário investimento na divulgação do mesmo.

Por último, as orientações oficiais - CBC, PCN e o PNLEM, mostraram ter parcela de contribuição para a escolha do livro didático. Apenas 4\% dos professores as consideram quando avaliam um LD. Essa pequena alusão dos professores às orientações oficiais de ensino pode estar relacionada ao envolvimento, de forma pouco ostensiva, das secretarias de educação em divulgar e motivar os educadores a seguirem a política pedagógica ou pela baixa correlação que fazem entre as orientações oficiais e a proposta didática do livro/autor.

Embora, assumir uma postura de avaliador profissional não seja uma tarefa fácil, ela faz-se necessária, pois a indicação de um livro didático para os alunos(as) das escolas das rede pública estadual passou a ser exigência da SEEMG e, caso o professor não o faça, outros farão por ele. Cabe aos órgãos governamentais atuarem de forma plena para envolver o professor na escolha do LD. As editoras, por sua vez, devem atentar para a diversidade de programas de ensino para a educação básica e fomentar produções identificadas com diferentes propostas. Por último, mas não menos importante, os programas de formação continuada precisam dar suporte a uma análise esclarecedora, a partir de critérios explícitos e objetivos para que o professor não seja ludibriado pelo marketing editorial e possa fazer escolhas segundo as necessidades formativas de seus alunos(as). 


\section{REFERÊNCIAS BIBLIOGRÁFICAS}

BAYARD, P. Como falar dos livros que não lemos? Rio de Janeiro: Objetiva: 2007.

BAKHTIN/VOLOCHINOV. Marxismo e Filosofia da Linguagem. São Paulo, Editora Hucitec, 1997. BRAIT, B. \& MELO, R. de. Enunciado/enunciado concreto/enunciação. In: BRAIT, B. (Org.). Bakhtin: conceitos-chave. São Paulo: Contexto, 2005.

BROWNE, J. “A Origem das Espécies” de Darwin. Rio de Janeiro: Jorge Zahar, 2007.

CASSAB, M. \& MARTINS, I. A escolha do livro didático em questão. IV Encontro Nacional de Pesquisa em Educação em Ciências. UFRJ, 2003.

GALILEU, G. A Mensagem das Estrelas. Rio de Janeiro: Mast, 1987.

MAYR, E. O Desenvolvimento do Pensamento Biológico. Brasília: UNB, 1998.

LAVOISIER, A. L. (1789). Tratado Elementar de Química. São Paulo: Madras, 2007.

LIMA, M. E. C. C. Formação continuada de professores: desafio de diretores. In: Procad - Fase Escola Sagarana. SEE-MG. Guia de estudo 5, 2001.

LIMA, M. E. C. C.; AGUIAR, O. G. \& PAULA, H. F. Formação e evolução de conceitos in: Ensino de Ciências por Investigação. V. 3. Coleção ENCI. Belo Horizonte: Ed. da FaE-UFMG (2009).

SANTOS, S. Critério para Avaliação de Livro Didático para o Ensino Médio. Distrito Federal: UnB, 2006. SOUZA, D. M. de. E o livro não “anda”, professor? In: CORACINI, M. J. R. F. (Org.) Interpretação, autoria e legitimação do livro didático: língua materna e língua estrangeira. Campinas, SP: Pontes, 1999. MOLINA, Olga. Quem Engana Quem: professor x livro didático. Campinas: Papirus, 1987. Programa Nacional do Livro Didático para o Ensino Médio - PNLEM.

Resolução n. 1, de 15 de janeiro de 2007 - PNLEM - FUNDO NACIONAL DE DESENVOLVIMENTO DA EDUCAÇÃO. 
